\title{
MICROGRID: A REVIEW
}

\author{
Abinash Singh ${ }^{1}$, Balwinder Singh Surjan ${ }^{2}$ \\ ${ }^{1}$ Research Scholar, ${ }^{2}$ Associate Professor, Electrical Engineering Department, PEC University of Technology, \\ Chandigarh, India
}

\begin{abstract}
The demand for high quality electricity and growing electricity consumption has been caused by increasing electrification of daily life causes and the rising number of sensitive or critical loads. Due to the rapid increase in global energy consumption and the diminishing of fossil fuels, the customer demand for new generation capacities and efficient energy production, delivery and utilization keeps rising. The micro grid concept has the potential to solve major problems arising from large penetration of distributed generation in distribution systems. A proper control strategy should be implemented for a successful operation of a micro grid. Different load models can be simulated and analyzed using MATLAB and PSCAD software. In this paper, the work done in the field of Micro Grid has been reviewed.
\end{abstract}

Keywords: DER, MG, PCC, PV, VSI.

\section{INTRODUCTION}

A small scale system and located near the consumer is called the Micro-Grid (MG) system. The interconnection of small generation to low voltage distribution systems can be termed as the Micro Grid. Micro Grids can be operated with and without a connection to the main power network. Small Capacity Hydro Units, Ocean Energy and Biogas Plants , wind, diesel-generation, PV, energy storage etc are the various energy resources in $\mathrm{MG}$ for electrification of areas mainly rural areas where there is no possible access to grid electricity due to poor access of remote areas to technical skills. The micro grid has to be designed in such a manner so that there is ease in installation, commissioning, operation and maintenances. The micro grid helps in reducing the Expenditure by reducing network congestion \&line losses and line costs and there by higher energy efficiency [1] - [3].

Today's challenge is the implementation of renewable energy into existing power systems. MG provide higher flexibility and reliability as it is able to run in both grid connected and islanded mode of operation and its components may be physically close to each other or distributed geographically [4],[5]. To meet the increasingly growing demand of electricity, and to improve energy utilization efficiency and reliability, new power generation technologies, including renewable energy, clean and efficient fossil fuels, distributed generations have been developed [6].The micro grid concept is based on the assumption that large numbers of micro generators areconnected to network to lower the need of transmission and high voltage distribution system [7].However the micro grid can be integrated with the distribution system but it can also produce a threat to the safe and reliable operation of the grid due to the net loss in line flow, voltage and power quality[6],[8].
This paper in organized as follows: Section II provides a brief description of the operation and control of micro grid. Section III presents the voltage \& power regulation and energy management in micro-grid. Section IV highlights the simulation works done for the different load models of micro grids. Lastly, the conclusions are drawn in Section V.

\section{OPERATION AND CONTROL}

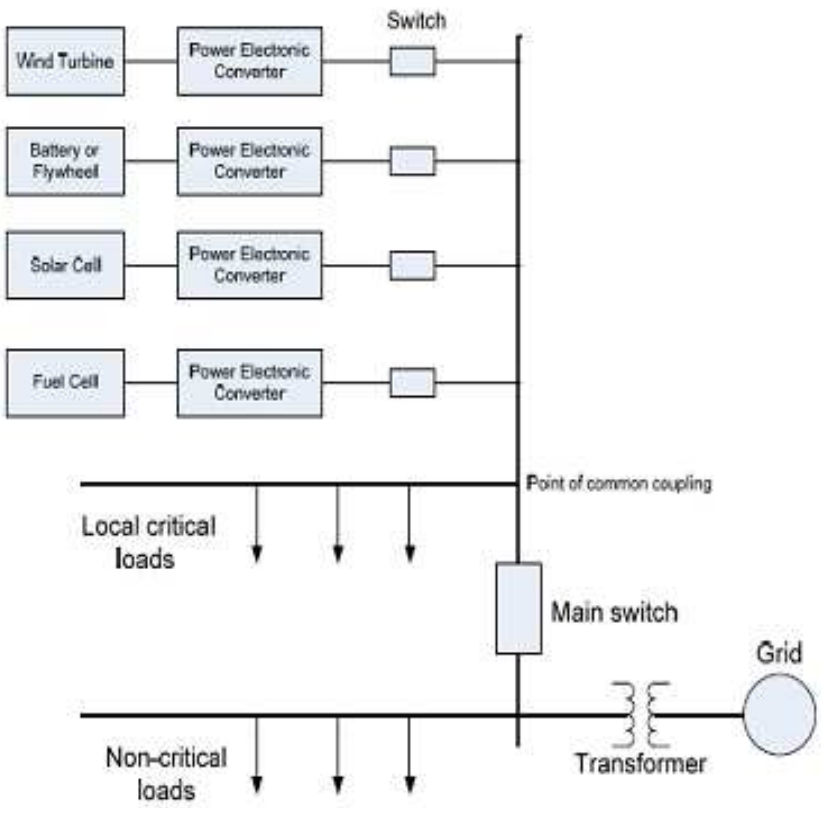

Fig- 1 Micro grid- A schematic diagram 
The traditional energy generation and distribution has an alternative today, named Micro Grid. And with the use of smart grid technologies, integrated control of distributed power generation can be achieved. Fig-1 depicts a normally operated MG in a grid-connected mode through the substation transformer via Point of common coupling (PCC). PCC is the point in the electric circuit where a micro grid is connected to a main grid. The converters play a vital role firstly by connecting DG systems in parallel with the grid or other sources, and secondly to continue functioning in stand-alone mode, when critical loads don't get supply from other sources [9].

The system can disconnect from the utility in case of faults and voltage collapses, and when the power quality from the grid reduces below certain standards. A centralized model controller is set in the micro-grid with the control logic optimization of main power for unplanned and planned mode conversion. When micro-grid works in grid-connected mode, the main power works in PQ mode and when the micro-grid works in islanding mode, the main power works in V-F mode so the control of the micro-grid is "master and slavery" control. The micro-grid work mode can be detected from the micro-grid information such as current, voltage etc [10].

The choice of the customer is the main reason for an upcoming market of Distributed Generation (DG). It depends upon them as whether to purchase their power from existing utilities or to use DG sources for the fulfillment of their power needs. A MG concept of production and supply of power can be formed, if all the customers can come together. Comparatively, the non autonomous micro grid (the paralleled micro grid) is the most beneficial mode of operation for both the utility and the customer [11].

For optimal operation of a group of Small Water Turbines integrated in a medium voltage AC grid, a variable speed solution has been proposed. The efficiency of hydro machines is increased as there is a large variation in water flow, so operation at variable speed is considered such that the connection to the $50 \mathrm{~Hz}$ power grid can be done using an AC/DC-DC/AC interface. The purpose of a reactive power and a harmonic voltage compensation and transfer of energy from generator to grid is achieved by the use of power electronic based interface [12].

In various sectors of electric power system, i.e. Generation, Transmission, and distribution, the competition among the utility service providers has been started due to deregulation and restructuring of old centralized power system and this originates the concept of MG. Some positive points of micro grid are reduction of 'Transmission line congestion', easy installation and control of its small distributed energy resources, combined heat and power operation, less sulphur and nitrous emission etc. The MG has been used as a slack bus and has been analyzed by Fast de-coupled load flow (FDLF) method in Compaq visual FORTRAN [13].

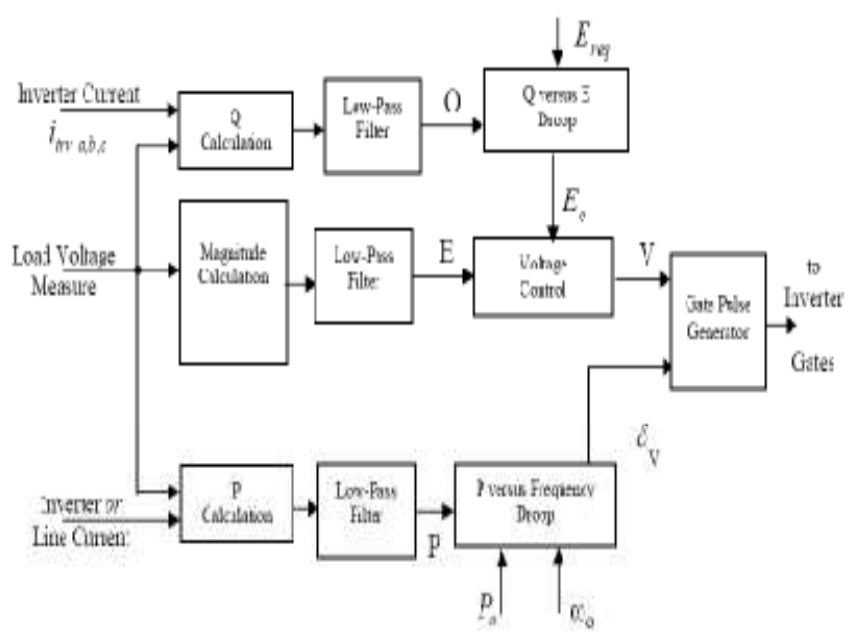

Fig- 2 Power vs. frequency droop control strategy

A MGMEG is capable to separate and isolate itself from the utility system, during a utility grid disturbance if they are well integrated and intelligently controlled by power electronic Voltage Source Inverter (VSI) for its operation with high power quality. For effective installation of distributed energy resource units and loads in different MGMEGs, a Multi agent technique and power vs. frequency droop characteristic control strategy of VSIs have been proposed as shown in Fig-2 [14].

Inverters are a universal interface to inject the power produced by distributed power generation in stand-alone loads, microgrid or the main electrical grid.

The droop control and inverse droop control have been discussed in order to manage the active and reactive power flows both in case of grid-connection and islanding operation mode [4].

For single micro grid, different control strategies are used to maintain the Stable output, which utilizes PQ control in grid connected mode and droop control together with v/f control in isolated mode. Combination of a series of control strategies are utilized to enable stable operation of micro grid in each mode, and switch smoothly between the two modes [15].

Micro-Grid system needs to be monitored and controlled to minimize effect of power quality problems during steady state, islanding operation and reconnection with conventional power system. For this a V/I measurement equipment of MG system having real time measure function and communication with PC via USB port has been used. Further this system serves for various purposes as investigation of transient state, monitoring of real-time operation and evaluate the power system quality [1]. 
The major driving factors for cost down are the modularity and scaling capability of PV inverters. To achieve robustness in electrical grid the efficiency optimization has to be targeted for system including inverter efficiency, in addition to maximum power tracking of PV modules [2].

The micro source three phase output voltage asymmetry due to a micro-source three-phase load imbalance could lead to working disorders and can even cause damage to electronic devices. To achieve a good control effect in load balance and imbalance two existing control strategies namely Sliding Mode Variable Structure Control (SMVSC) and compensation method have been introduced [16].

For the propose of trading electrical energy or to provide system support services, Virtual Power Plant (VPP) is used to aggregate a number of DER of various technologies with various operating pattern and availability that connected to various points in distribution network. Distributed Energy Resources (DER), i.e. DGs can be integrated with controllable loads and energy storages, into micro grid and Virtual Power Plant [7].

A plug \& play control approach has been presented, which can be implemented in electronic power processors interfacing distributed energy resources with residential micro-grids where number of active energy sources and generated power vary during daytime, for providing full utilization of energy sources and reduction of distribution losses. Accordingly, for efficient operation supply and load variations, the residential micro-grids can automatically turn from grid-connected to islanded operation [17].

A multi-agent based control framework with Particle swarm optimization (PSO) has been proposed for energy and comfort management in integrated smart building and micro-grid systems which is made up of a central coordinator-agent and multiple local controller-agents [18].

The risk assessment differences between the traditional power grid and the smart grid has been presented. The smart grid risk assessment system and risk control measurement have been discussed using the latest self-healing concept in smart grid which is of great importance [19].

To form an effective communication subnet between equipments, distribution, generation, and dispatching centre, a novel electric information transmitting algorithm(EITA), has been proposed which is based upon distributed agent technologies and traffic engineering [20].

Smart meters and/or pre-paid meters can be used for monitoring the power consumption from utility and electricity bill. The pricing, renewable energy output, load demand, storage, and forecasting, decisions are made and communicated by a central intelligent unit and thus providing a supporting power in cases of power cut, blackouts, grid failure, and peak demand, as well as results in minimum purchase from the utility resulting in low electricity bill of user and ensures continuity of power [21].

Since the synchronization of microgrids that operate with multiple DGs and loads cannot be controlled by a traditional synchronizer so an active synchronizing control scheme has been proposed by adopting the network-based coordinated control of multiple DGs and thus providing a reliable connection to the grid [22].

Object Linking and Embedding for Process Control (OPC) protocol has been implemented as a supervisory control system for a controllable DER fuelled by producer gas, sharing a common load with a non-controllable DER. A user interface for the same has been developed where the existing automation hardware in a plant can be utilized for controlling DER's [23].

The main function of the overall architecture and key technologies in the MG platform, such as power technology, plug and play technology and optimization technology have been analyzed [24].

For the successful realization of smart grid main challenges includes the integration of renewable energy resources, real time demand response and management of intermittent energy resources. It has been stated that, the recent advancements in information and communication technologies (ICTs) could facilitate the effective development of the future micro-grid system by improving the system performance, modeling, monitoring and controlling of the micro-grids [25].

To improve the parallel operation of two micro hydro power plants (MHPPs) on an islanded micro-grid (MG) a control strategy has been presented. The two MHPPs are equipped with fix-speed turbines that drive induction generators (IG).

Fig- 3 shows the proposed control system as a combination of a voltage source inverter (VSI) with a dump load (DL) on its DC side and stepped capacitors. The MG frequency is stabilized by VSI as it operates at constant frequency [26]. 


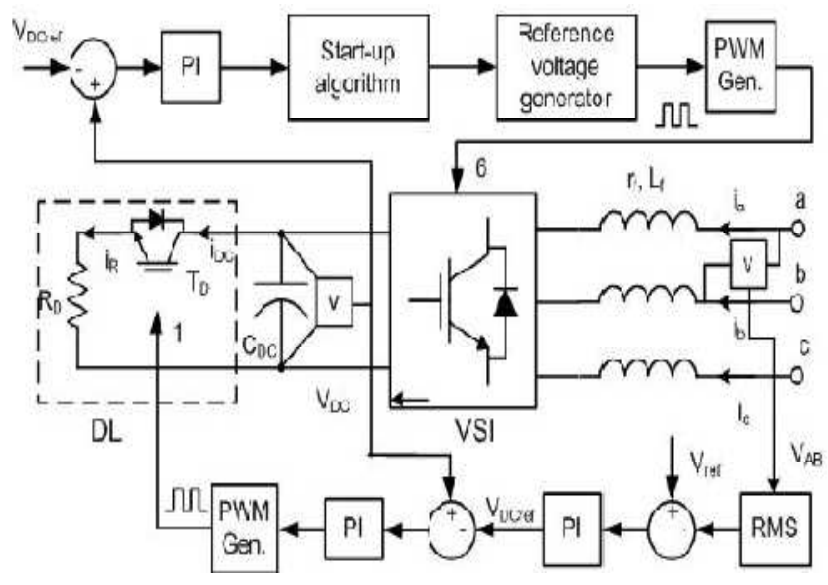

Fig- 3 The VSI+DL control strategy

To ensure system security, reliability and economical running under different control strategies for distributed power, the coordinated control of micro-power and energy storage devices can maintain the isolated network operation of MG [27].

The performance profiles of various micro-grid configurations under different operational scenarios have been presented. Distributed Energy Resources (DER) can also feed excess power, if any, to the utility grid, while delivering the power to the local areas at the installed location efficiently and reliably [28].

The power generated from the renewable power sources is strongly dependent on the natural conditions and therefore has the nature of unpredictability and fluctuation so the optimal operation planning method should be taken into consideration of the uncertainties of renewable power generations and load demand is proposed and studied [29].

A much faster and robust vector control algorithm based strategy has been implemented for a two-level IGBT full power converter, to operate the wind generation, with a hybrid DC-AC link topology, either in Maximum Power Point Tracking (MPPT) mode, or non-MPPT mode with enhanced tracking performance [30].

An important optimization task of power systems is the daily operational scheduling of decentralized units. The smallscaled co-generation power units can be planned for electrical power generation and district heating in a micro-grid [31].

The dynamic characteristics of the micro sources and microgrid have been analyzed under fault or normal circumstances with different structure and different control methods. Dynamic analysis of micro-grid is based on the control strategy design of micro-grid energy balance and frequency stability [6].
For the analysis of electrical sources of the micro-grid and to test its dynamic operation, HOMER $\AA$ and EUROSTAG® software have been used. To obtain the optimal configuration of hybrid renewable energy a sensitivity analysis has been performed based on different combinations of the generating system. EUROSTAG® software has been used to investigate the operation of the obtained architecture [32].

A building that has a very high energy performance, and with very low amount of energy requirement is known as 'Nearly Zero-Energy Buildings' (NZEB). And such a case study of a microgrid arranged for a complex of two commercial/residential has been presented and a load management strategy has been presented [33].

A two-degree-of-freedom active damping controller has been proposed to stabilize the newly introduced oscillatory dynamics to stabilize the micro-grid system in the presence of IM loads. The stability analysis and stabilization of MV droop-controlled micro-grids with IM loads has been presented [34].

A novel control strategy for VSCs and an energy storage system in a VSC-based microgrid without communication link has been proposed along with a novel hybrid model of VSCbased DGs. The conventional load frequency control techniques are inappropriate because in VSC-based micro grids, which use droop controller method, the desired frequency of VSCs is altering regarding the output active power [35].

The waste heat in MG can be used by placing the sources near the heat load. To isolate the microgrid's load from the disturbance, the generation and corresponding loads can be separated from the distribution system without harming the transmission grid's integrity [36].

The PV inverter is controlled as a current source following a reference active and reactive power with the active power being a function of the system frequency. A wireless communication among the renewable energy sources has been achieved for continuous monitoring by using frequency as control signal. The battery converter has been controlled with variable-frequency, variable-amplitude sinusoidal PWM modulation [37].

\section{POWER AND ENERGY MANAGEMENT}

\subsection{Energy Management in Micro Grid}

An energy management program for grid-connected micro grid with renewable generation and electric vehicles has been proposed which aims to minimize energy cost based on forecasting of loads, prices and renewable generations and was solved with genetic algorithm and pattern search methods. The uncertainty problems have been solved by Monte Carlo methods [38]. An effective approach to control Flywheel 
Energy Storage System (FESS) in distribution power automation environment has been proposed which includes the distributed control mechanism design for physical components of FESS, and intelligent decision and planning strategies for FESS charging and discharging procedure [39].

The problems including purchased energy from the main grid, DGs' operational cost, start-up and shut-down costs, and finally the cost of interrupted loads have been formulated. In order to determine the optimal generation of each DG and the amount of controllable loads during a day, the component models of micro grids consisting of a wind turbine, a micro turbine, a photovoltaic array and a fuel cell have been determined by using real data and the cost of micro grid has been minimized [40].

A photovoltaic (PV) based micro grid with combined energy storage using batteries and super capacitors with high energy and power density has been proposed (Fig-4) and the control strategy has been validated for different atmospheric and load conditions.

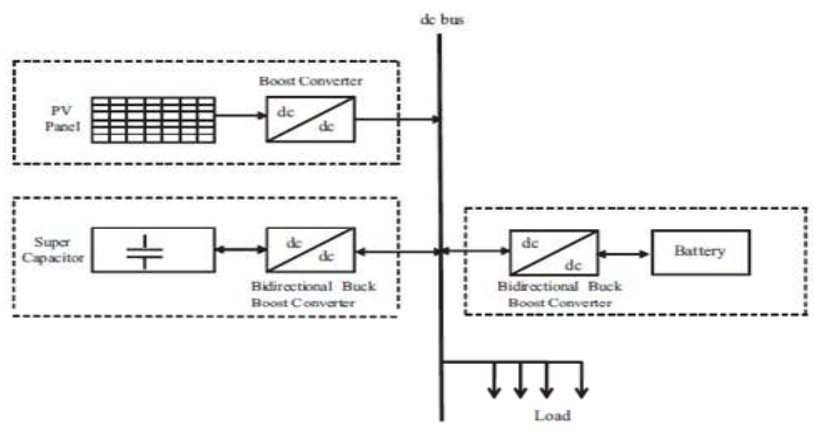

Fig- 4 PV Based Micro Grid with Battery and Super Capacitor Combined Storage

A concept to generate realistic load models of individual homes with a high resolution has been presented [42].

For micro grid energy management, a novel double-layer coordinated control approach, consisting of two layers: the schedule layer and the dispatch layer has been proposed. An economic operation scheme based on forecasting data is obtained by schedule layer, while the power of controllable units based on real-time data is provided by dispatch layer. Errors between the forecasting and real-time data have been resolved through coordination control of the two layers [43].

An optimized scheduling of a micro-grid battery storage system has been presented that takes into account the next-day forecasted load and generation profiles and spot electricity prices, to reduce running costs by optimally scheduling the generation and/or storage systems [44].
The application of Distribution Static Compensators (DSTATCOM) in Smart Micro-Grid (MG) has been presented as shown in Fig-5.

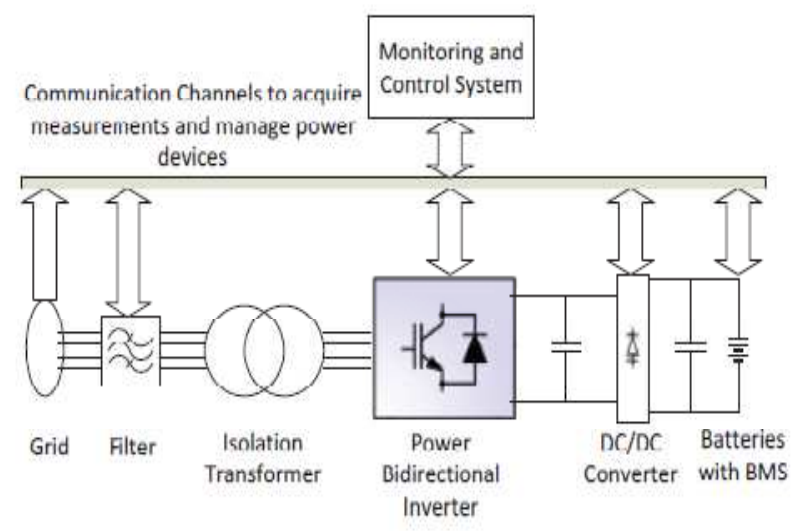

Fig- 5 D-STATCOM with battery storage

An overview on D-STATCOMs has been reported, describing out their layout, components and possible functions, either in presence of energy storage system or not. Finally the problem of management of these devices for application in Smart MG has been analyzed, while focusing on the choice of the communication technologies for data exchange with an Energy Management System (EMS) [45].

\subsection{Examples of Actual Site Implementation.}

An innovative wind/PV/diesel hybrid system along with advanced power electronics and control technology has been implemented in three remote islands in the Republic of Maldives whose design methodology and preliminary results have been presented. [46].

There are needs to develop a balanced Distributed Generation strategy which takes into account future integration with small, midsize and large regional projects due to the high cost for the construction of UHV/EHV transmission lines. A bottom up approach has been recommended through an evaluation of autonomous or non-autonomous modified Micro Grids concept to provide electricity to local residents and which serve as basic building blocks for future system expansion [47].

Different policies of on-grid and off-grid rural electrification in Nepal have been reviewed which have been imposed by two different organizations, namely, Nepal Electricity Authority and Alternative Energy Promotion Centre. Also, different issues in rural electrification have been identified on connection of micro hydropower and mini grid development [48]. 


\subsection{Protection Issues in Micro Grid}

Earlier protection systems associated with medium and low voltage networks were designed on the basis of unidirectional power flows, using the time coordinated over current relays for protection against network faults. Regarding distributed generation, these systems have undergone the changes over the recent decades, along with the fact that many of these sources can be connected to form independent micro grids, have challenged this protection perspective [49]. Implementation of adaptive protection system using digital relaying and advanced communication has been stated as a successful method of the protection of micro grid [50].

A protection scheme for a DC micro-grid has been suggested. A 400V DC micro-grid consisting of a wind power system (Permanent Magnet Synchronous Generator, PMSG), a photovoltaic system, a fuel cell system and energy storages have been presented considering abnormal operating conditions during various faults [51].Some technical challenges on micro grid with respect to voltage and frequency control, islanding and protection of micro grids have been presented [52].

An operational safety design concept and fault mitigation technique has been proposed to ensure confidence in protection system. The multifunctional intelligent digital relay has been used for the micro grid protection and safety concept with central control and monitoring unit for adaptive relay settings strategy for micro grid protection [53].

\subsection{Voltage and Power Regulation in Micro Grid}

To guarantee voltage regulation and harmonic cancellation at the load site in the presence of distributed generation an application of a controller based on state space design for a Shunt Active Filter with energy storage (SAFES) within a local power supply network has been presented [54].

To meet the load demand and maintain the voltage and frequency stability with the change in voltage amplitude and phase of PWM converter, generators may create active and reactive power neatly. PWM converters can improve the generators' power factor to unity, and produce less harmonics and thus improving the power quality [55].

To improve the reactive power control and sharing accuracy, an accurate reactive power sharing algorithm functions have been proposed by estimating the impedance voltage drops. Power control strategy containing a virtual inductor at the interfacing inverter output and an accurate power control and sharing algorithm has been proposed with consideration of both impedance voltage drop effect and DG local load effect [56].

A multiple converter scheme has been proposed which makes the micro-grid system capable of low voltage ride and making the system more reliable and stable. The control strategy of additional power converter connected in parallel with main converter has been discussed to support extra reactive power to withstand the severe voltage dip [57].

The use of Static Synchronous Compensator (STATCOM) and battery energy storage system (BESS) has been investigated for the purpose of stabilizing the micro-grid voltage during short circuit faults in islanded mode of operation to continue power supply to the customers and thereby increasing the reliability of the power system [58].

To overcome the power quality problems, the Static Var Compensators (SVC) based on the combination of Thyristor Switched Capacitors (TSC) and Thyristor Controlled Reactors (TCR) or SVC combined with Active Power Filters (APF) has been proposed [59].

To decrease losses, generation costs and overload in transmission lines during the peak time a management model for optimized consumption reduction has been introduced [60].

A new power line conditioner called Universal Power Line Manager has been proposed for micro grid to overcome many power quality issues like voltage sag, swell, power frequency variation, and harmonics. UPLM is based on the combination of UPQC, UPFC and frequency changer (matrix converter) [61].

PSO based PSS has been designed for low and medium of the MG considering the power sharing stability of a grid connected Micro-grid (MG) system with three Distributed Generation (DG) units via Power System Stabilizer (PSS). Various PSS structures have been employed and compared in order to achieve the best transient response under different DG penetration levels to tune the controller parameters PSO has been used [62].

To achieve the plug-and-play, and for flexible application of D-FACTS to the micro grid, the concept of Power Electric Building Block (PEBB) has been introduced into micro grid. The main functions of several typical D-FACTS in the micro grid have been reviewed [63].

A comparative analysis has been presented between two power conditioners connected to a four-wire micro-grid. One of which has been developed on a two levels voltage structure and the other on a three-level voltage NPC structure (Neutral Point Clamped), but both controlled by the same strategy to limit the disturbance produced by different loads [64].

The frequency regulation has been achieved by designing Distributed Energy Resources or DERs to exhibit an outputfrequency-versus-power characteristic similar to the speedversus-power (droop) characteristics of conventional turbo- 
and hydro-generators. It is important to regulate the amplitude and frequency of the voltages throughout the MG system [65]. The harmonic current brought by power electronic devices and load with considerable reactive power demand are the most significant factor influencing power quality of microgrid.

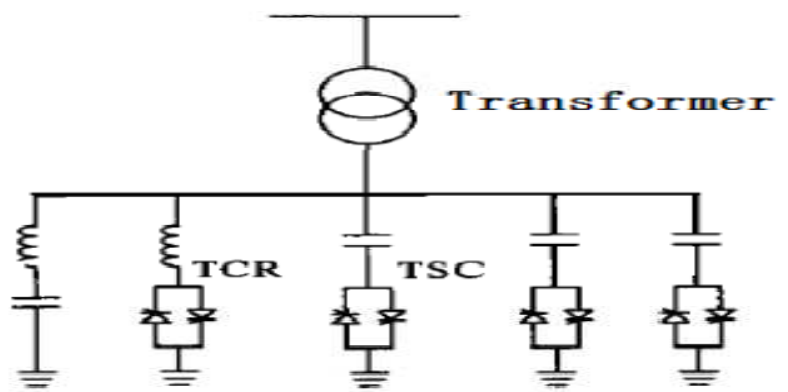

Fig- 6 General Structure of SVC

Fig- 6 shows a combined system of Active Power Filter (APF) and Static Var Compensator (SVC) that has been introduced to improve power quality of microgrid. APF has been installed at the outlet of the micro source inverter to mitigate harmonic current. The ip-iq method is used for current detection and Deadbeat Control and Space Vector Pulse Width Modulation (SVPWM) are used as tracking method [66].

The use of a Micro Grid Voltage Stabilizer (MGVS) as a controller has been proposed for the improvement of the dynamic voltage stability in a microgrid. The MGVS is a secondary level voltage controller generating a control signal and this control signal is further divided among the reactive power sources in the micro grid in proportion to their available capacities; thus each source will be required to generate certain amount of reactive power [67].

A three-phase Active Power Conditioner (APC) has been introduced to improve power quality in micro grids based on renewable energy. APC acts as an interface between renewable energy sources and the $\mathrm{AC}$ bus of a micro grid and uses an improved control strategy, which makes possible to inject energy in the micro grid, compensate the current harmonics and correct the power factor [68].

A new application of the UPFC has been introduced addressing the voltage stability concern in the MG in low and medium voltage system. The slightly modified UPFC can be used to improve the voltage profile of the micro-grid with or without grid connectivity [69].

To improve the quality of power supply, an optimal power control strategy has been proposed for an autonomous micro grid operation based on a real-time self-tuning method where Distributed Generation (DG) units are connected to the grid.
Particle Swarm Optimization (PSO) along with PI regulator has been proposed for real-time self-tuning of the system [70].

\section{SIMULATION AND MODELLING EXAMPLES}

The microgrid using renewable energy consist of a $3 \mathrm{~kW}$ photovoltaic, with 30 pieces of $12 \mathrm{~V}$ for $100 \mathrm{Ah}$ battery bank, $\mathrm{DC} / \mathrm{DC}$ converter, charge controller for battery, single phase $\mathrm{DC} / \mathrm{AC}$ inverter and various loads (resistor, capacitor, inductor) have been developed and simulated by Matlab/Simulink software as shown in Fig- 7.

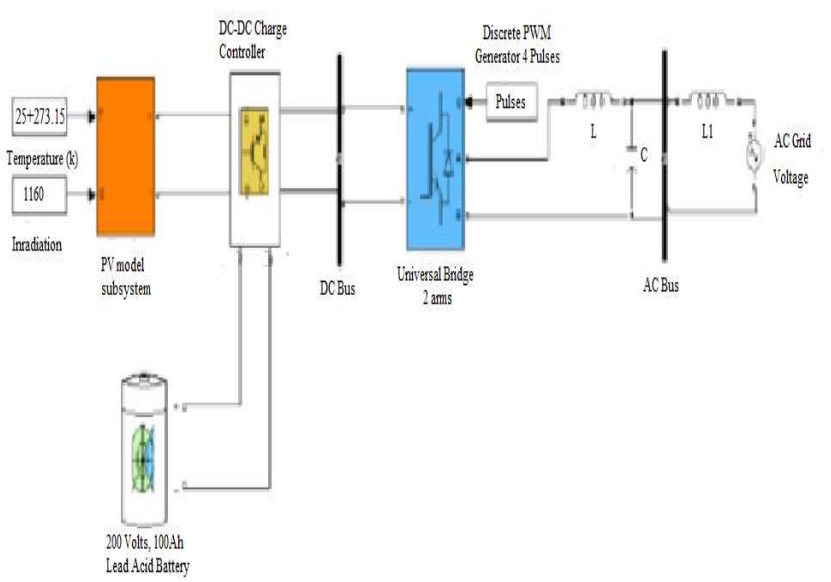

Fig- 7 Configuration of the micro grid test bed using PV and battery based power generation

The mathematical model of system components has been introduced in order to investigate the dynamic behavior of each system [71].

A Matlab/Simulink model of micro grid has been developed, incorporating an energy storage system, such that when the demand is less, the charging of battery takes place and vice versa. Also, depending on the frequency variations, the $\mathrm{ON}$ and OFF of the non-critical loads were done automatically and the status of the battery and the different loads are decided by the control unit [72].

Synchronization of a Micro-grid with the main network must be done when the voltage of micro-grid is in synchronization with the voltage of main network. Phase-locked loops have been used for detection of phases of micro-grid and main network voltages and when the two voltages were synchronized, micro-grid is connected to the main network [73].

For control of generators during faults, generator trip, surges and switching conditions the transient behavior of DGs in simulated environment has been analyzed. The dynamic modeling of a micro grid operating in Grid-Connected mode has been applied to a distributed utility grid that uses three gas turbine based Distributed Generators (D.G.), generating power 
at distribution voltage level (415 volts) and these are connected to a MV grid through a transformer [3].

The impact of the load's voltage and frequency dependence on the micro-grid's frequency and voltage deviation during a planned islanding condition has been modeled and analyzed using PSCAD/EMTDC. It has been examined that the frequency deviations and voltage deviation during micro-grid operation are dependent on each other. Load sharing among different DG, during micro-grid operation, could be accomplished by equipping each DG with a P-f and Q-V droop characteristic [74].

For satisfying the demand of flexible control in micro-grid and for easy mode conversion an inverter controller has been used which is shown in Fig-8.

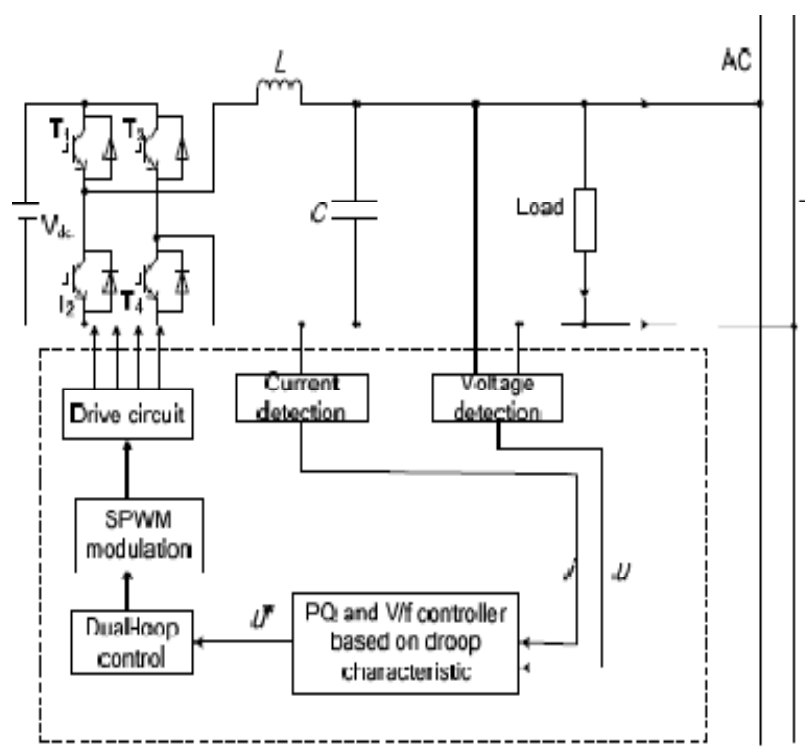

Fig- 8 The control diagram of the inverter unit in micro-grid

When the micro-grid is connected to the main grid, PQ control with droop characteristic is adopted for the inverter and when micro-grid separates from the main grid, V/f control with droop characteristic has been used [75]. A micro-grid system based on wind and hydropower sources has been presented and issues related to operation, control, and stability of the system have been addressed by investigating a case study in Newfoundland, Canada. The system has been modeled and simulated using Matlab/Simulink, and the operational modes and technical challenges have been investigated [76]. An integrated model for a Photon Exchange Membrane (PEM) fuel cell generator including the power conditioning devices that can be used as a micro grid have been described and its block diagram can be seen in Fig-9.

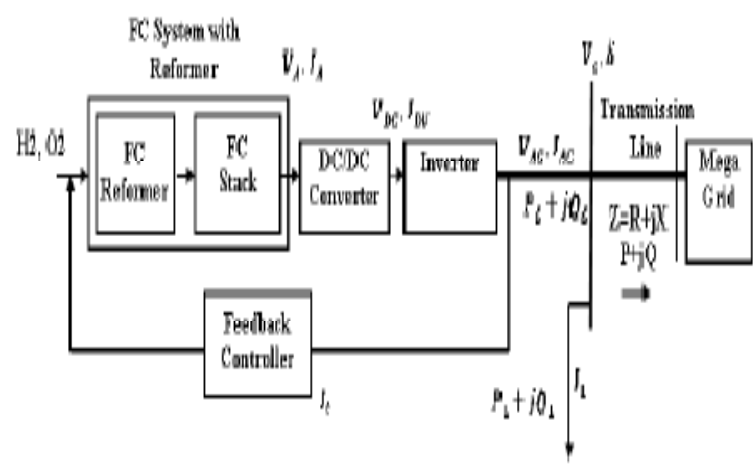

Fig- 9 Block diagram of a fuel cell generator

A detailed model of the fuel cell, power conditioning devices and a Voltage Source Inverter (VSI) with no major assumptions has been developed in Matlab® and Simulink ${ }^{\circledR}$ and the integrated designs have been validated with a reallife1KW fuel cell kit [77]. A micro-grid with PV-WindDiesel generator hybrid system has been modeled with a DC/AC inverter with a pre-defined Maximum Power Point Tracking (MPPT) control and its operations have been discussed. This complete system has been modeled in PSCAD/EMTDC software and the performance of the system has been analyzed [78].

An effective multi-loop controller has been designed to achieve the smooth changing between the utility connected operation and the islanding operation. To facilitate load power sharing by automatically adjusting the voltage and frequency of system at the conversion between the two modes, an integrated application of PQ control and droop control has been simulated in a micro-grid system containing micro turbine [79].

A new droop control method has been validated through simulations by PSCAD software which can re-adjust the deviation in voltage and frequency, maintain the voltage and frequency. Such a MG structure used for simulation is shown in Fig- 10.

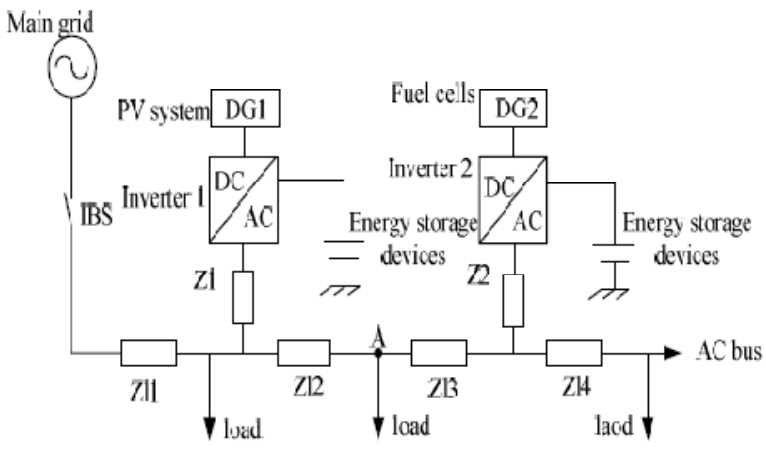

Fig- 10 Micro-grid structure used for simulation 
To achieve secondary regulation of the voltage and frequency and to minimize the steady-state error on the nominated operation point, the voltage reference compensation has been implemented [80].

Real-time Hardware-in-the-Loop (HIL) simulation has been proposed as an effective technique to include complexity of the micro-grid under control in the testing real-time embedded system. Dynamical models of various renewable energy sources and converters have been developed and Control strategies under the grid-connected mode and the islanding mode and transitions between these two modes have been addressed [81].

A method of micro grid paralleling with large grid based on back to back VSC has been proposed consisting a double-loop control strategy in which fuzzy control increases dynamic response and voltage \&frequency stability of grid paralleling [82].

Distributed Generation (DG) systems such as Photovoltaic (PV) and wind energy systems are essential parts of the future smart grids.

To provide reactive power compensation, and power factor improvement at the PCC for a grid connected PV/fixed speed wind driven micro grid, a smart interconnection control strategy has been proposed (Fig- 11) which is based on the control of the PV coupling Voltage Source Inverter (VSI) ensuring dual active/reactive power operation of the VSI [83].

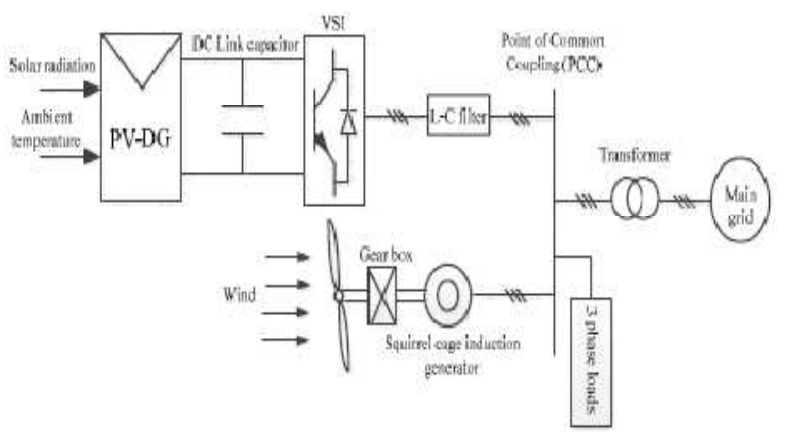

Fig- 11 System architecture of the PV/Wind based micro grid connected to the utility

In order to compensate the effect of power quality during the grid- connected process, the power flow in the micro-grid has been analyzed based on the characteristic of frequency and active power. Grid-connected control method and simulations of the micro-grid have been presented. The frequency of the micro-grid should be lower than that of the main grid before being connected and the difference value of the voltage between the micro-grid and the main grid should be very small [84].
PSCAD/EMTDC has been used to verify the feasibility and to validate a novel approach that has been presented to share the harmonic and reactive currents of a micro-grid using scattered multi-functional grid-connected inverters (MFGCI) without communication wires [85].

A case study on impact of Fuel Cell operation on the frequency stability of electric grid has been carried out. FC system can contribute to frequency stability in both cases when the load increases and also when the load drops if it is operated along with a hybrid Wind-PV System.

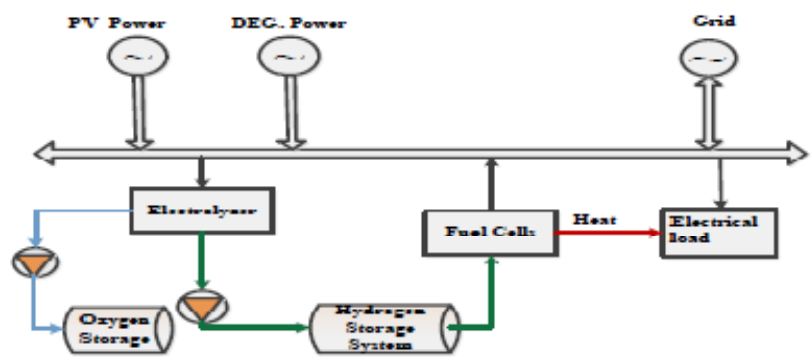

Fig- 12 Schematic diagram of a hybrid system connected to a Micro-Grid.

The modeling and control of a hybrid Photovoltaic (PV), Diesel-Engine Generator (DEG) - Fuel Cell (FC) system connected to electric grid has been presented. Schematic diagram of such a hybrid system connected to a Micro-Grid is shown below in Fig-12 [86].

A comprehensive analysis has been conducted by time domain simulations using Matlab/Simulink software. The use of dynamic voltage restorer as series compensation to ensure successful islanding in case of double line to ground fault and three phase to ground fault has been proposed, whose single line diagram is given in Fig- 13[5].

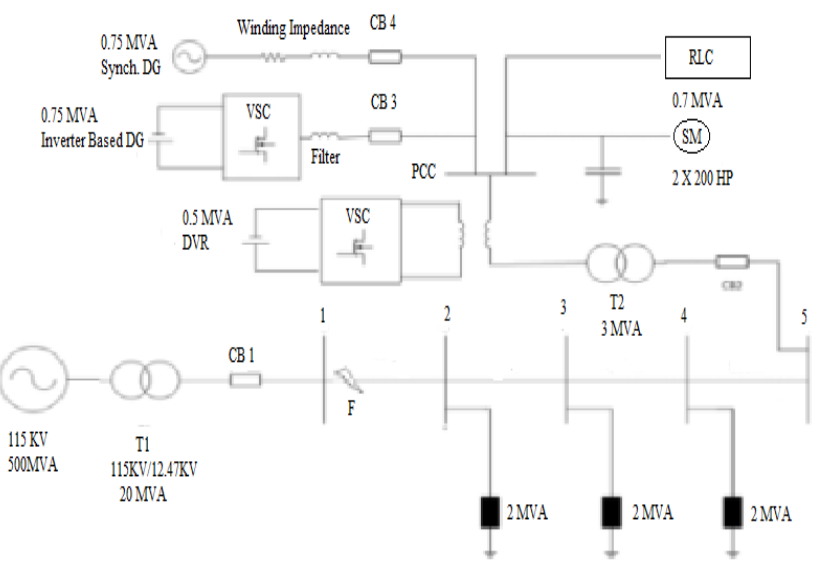

Fig- 13 Single line diagram of DVR installed on PCC in micro grid 
To improve voltage quality, and power supply reliability in a micro grid, a dynamic voltage restorer (DVR) based on photovoltaic (PV) generation/battery units has been proposed. The DVR has been connected with the grid by a rectifier, which is in series with the point of common coupling (PCC) [87].

A five level Cascaded H-Bridge for micro grid application has been proposed and a SIMULINK based model has been developed having the capability of utilizing different dc voltages on the individual H-bridge cells which results in splitting the power conversion amongst higher-voltage lowerfrequency and lower-voltage higher-frequency inverters [9].

To ensure accuracy, the dynamic models of individual components have been integrated to form a micro grid dynamic simulation system in the Matlab/ Simulink environment. The dynamic operations of a low-voltage micro grid with various distributed energy resources have been analyzed with a sample system consisting of a $30 \mathrm{kVA}$ microhydro generator, a $30 \mathrm{kVA}$ diesel engine generator, a $30 \mathrm{kVA}$ gas engine generator, and a $15 \mathrm{kVA}$ micro-wind turbine generator as well as loads [88].

\section{CONCLUSIONS}

After going through this review based on the given title, it has been concluded that issues of unreliable power quality, increased focus on renewable energy, need for rural electrification, and focus on higher efficiency have resulted in more emphasis on developing micro grid infrastructure. The ability of MG to island generation and loads together has a potential to provide a higher local reliability than that provided by the power system. Regarding distributed generation, the distribution systems have undergone the changes over the recent decades, along with the fact that many of these sources can be connected to form independent micro grids, have challenged this protection perspective. Among various techniques reviewed and considering future scope, more case studies of actual sites of MG can be done and some extended emphasis should be laid on issues of micro grid like protection issues, power system stability and further the implementation of FACTS devices in existing micro grid can help to maintain power quality and better power flow and all of these can be analysed in MATLAB and PSCAD.

\section{REFERENCES}

[1]. Tae-young Lee, Kwang-ho Ha, Hyun-jeaYoo, Jong-wan Seo and Myong-chul Shin, "Research for Data acquisition equipment with micro-Grid system", 5th International Conference on Electrical and Computer Engineering, IEEE, Bangladesh ,2008, pp. 712-715 .

[2]. Xiaoming Yuan and Yingqi Zhang, "Status and Opportunities of Photovoltaic Inverters in Grid-Tied and Micro-Grid Systems", IEEE Power Electronics and Motion Control Conference, vol.1, Shanghai,2006, pp. 1 - 4
[3]. T.K. Panigrahi, A.K. Saha, S. Chowdhury, S.P.Chowdhury, N.Chakraborty, Y.H.Song, S.Byabortta, “A simulink based micro grid modeling \& operational analysis using distributed generators", Proceedings of the 41st International Universities Power Engineering Conference, vol. 1 ,Newcastle, 2006, pp. 222-226.

[4]. A. Nagliero, R. A. Mastromauro, V.G. Monopoli, M. Liserre and A. Dell'Aquila, "Analysis of a universal inverter working in grid-connected, stand-alone and micro-grid", IEEE International Symposium on Industrial Electronics, Bari, 2010, pp. 650- 657.

[5]. Mazheruddin H. Syed, H.H. Zeineldin and M.S. El Moursi, "Grid Code Violation during Fault Triggered Islanding of Hybrid Micro-grid", IEEE PES Innovative Smart Grid Technologies, Washington DC,2013, pp. 1-6.

[6]. Liu Qiang, Zhou Lin, Guo Ke," Review on the Dynamic Characteristics of Micro-grid System", IEEE Conference on Industrial Electronics and Applications, Singapore, 2011, pp. 2069-2074.

[7]. Elaheh Mashhour, S.M., Moghaddas-Tafreshi, “A Review on Operation of Micro Grids and Virtual Power Plants in the Power Markets", IEEE International Conference on Adaptive Science and Technology, Accra, 2009, pp. 273-277.

[8]. Jing Wang, Zhiqi Wang, Lingling $\mathrm{Xu}$ and Zongli Wang, "A Summary of Applications of D-FACTS on Microgrid", IEEE Asia Pacific Power And Energy Engineering, Shanghai, 2012, pp. 1-6.

[9]. K.Venkateswarlu, J.Krishna Kishore, "Modeling and Simulation of Micro Grid System Based on Renewable Power Generation Units by using MultilevelConverter", International Journal of Engineering Research \& Technology, Vol. 1, Issue . 6, August 2012.

[10]. Zhaoyun ZHANG, Yanxin LI, Wei CHEN, "The Research on Micro-grid Mode Conversion" , China International Conference on Electricity Distribution, Shanghai, Sep. 2012,pp. 1-7.

[11]. Cameron L. Smallwood, P.E,“ Distributed Generation in Autonomous and Non-Autonomous Micro Grids", IEEE Rural Electric Power conference, Colorado Springs,2002, pp. D1 D1_6.

[12]. R. Magureanu, M. Albu, V. Bostan, A.M. Dumitrescu, G. Dimu, F. Popa and M. Rotaru, "Smart AC Grid Integrating Dispersed SmallHydropower Sources", 11th International Conference on Optimization of Electric and Electronic Equipment, Brasov, 2008, pp. 345-350.

[13]. A.K.Basu, S.P.Chowdhury, S.Chowdhury, D.Ray, P.A.Crossley, "Reliability Study of A Micro-Grid Power System", 43rd International Universities Power Engineering Conference, Padova, 2008, pp. 1-4.

[14]. Mao Meiqin, Liuchen Chang, Ding Ming, "Integration and Intelligent Control of Micro-Grids with Multi-Energy Generations: A Review", IEEE International Conference on Sustainable Technologies, Singapore,2008, pp.777-780.

[15]. Zhou Xue-song, Cui Li-qiang, Ma You-jie, "Research on Control of Micro Grid", Third International Conference on 
Measuring Technology and Mechatronics Automation, IEEE, Shanghai, 2011, pp. 1129-1132.

[16]. QunhaiHuo, Xisheng Tang and Li Kong, "Study of Three Control Strategies for Micro-source Local Load Imbalance in Micro-grid", IEEE International Conference on Sustainable Power Genereation And Supply, Nanjing, 2009, pp.1-4.

[17]. Paolo Tenti, Alessandro Costabeber, Daniela Trombetti and Paolo Mattavelli, "Plug \& Play Operation of Distributed Energy Resources in Micro-Grids", IEEE International Telecommunication Energy Conference, Orlando, USA, June 2010, pp. 1-6.

[18]. Zhu Wang, Rui Yang and Lingfeng Wang, "Intelligent Multi-agent Control for Integrated Building and Micro-grid Systems", IEEE PES Innovative Smart Grid Technologies, Hilton Anaheim, Jan. 2011, pp.1-7.

[19]. Hui Hou, Jianzhong Zhou, Yongchuan Zhang, Xiongkai $\mathrm{He}$, "A Brief Analysis on Differences of Risk Assessment between Smart Grid andTraditional Power Grid", Fourth International Symposium on Knowledge Acquisition and Modeling, Sanya, Oct. 2011, pp. 188-191.

[20]. Yang Ting, Yan Yanhan, Wu Jiaowen, Cao Zhiheng, Li Ang, "Distributed Metering Information Control Algorithm in Smart Micro Grid", IEEE 3rd International Workshop on Intelligent Systems And Applications, Wuhan, May 2011, pp. $1-3$.

[21]. Akshay K. Rathore, "Hybrid Micro-grid $(\mu \mathrm{G})$ Based Residential UtilityInterfaced Smart Energy System: Applications for Green Data Centers and Commercial Buildings", 7th IEEE Conference on Industrial Electronics and Applictions ,Singapore, July 2012, pp. 2063-2068.

[22]. Changhee Cho, Jin-Hong Jeon, Jong-Yul Kim, Soonman Kwon, Kyongyop Park and Sungshin Kim" Active Synchronizing Control of a Microgrid", IEEE transactions on power electronics, vol. 26, no. 12, December, 2011, pp. 37073719.

[23]. VineetKoshy Philip, Siby Jose, Ashok S, "Application of OPC Protocol in IslandedMicro Grid Automation", Second International Conference on Sustainable Energy and Intelligent System (SEISCON) Chennai, 2011, pp. 560-563.

[24]. Siyao, FENG, Wenjun YIN, Haifeng WANG, "Integrated Micro-grid optimization and control technology", The International Conference on Advanced Power System Automation and Protection, IEEE, Beijing, Oct. 2011, pp. 2072-2075.

[25]. MeysamShamshiri, Chin Kim Gan, Chee Wei Tan," A Review of Recent Development in Smart Grid and Micro-Grid Laboratories", IEEE International Power Engineering and Optimization Conference, Melaka, Malaysia, June, 2012, pp. 367-372.

[26]. C. P. Ion, C. Marinescu, "Autonomous micro-grid based on micro hydro power plants", 13th IEEE International Conference on Optimization of Electric and Electronic Equipment, Brasov, May 2012, pp. 941-946.

[27]. Yongqin GU , Peiqiang LI , Yuan PAN, Hui OUYANG , Dong HAN, Yuanzhao HAO, "Development of Micro-grid
Coordination andControl Overview", IEEE PES Innovative Smart Grid Technologies (ISGT), Tianjin, May 2012, pp. 1-6. [28]. ParimitaMohanty, G Bhuvaneswari and R Balasubramanian," Optimal planning and design of Distributed Generation based micro-grids", 7th IEEE International Conference on Industrial And Information Systems, Chennai, Aug. 2012, pp. 1-6.

[29]. AngoSobu Non-Member, IEEE and Guohong Wu Member, IEEE," Optimal operation planning method for isolated microgrid considering uncertainties of renewable power generations and load demand", IEEE PES Innovative Smart Grid Technologies (ISGT), Tianjin, May 2012, pp.1-6. [30]. Lijun He, YongdongLi and Ronald Harley," Novel Adaptive Power Control of a Direct-Drive PM Wind Generation System in a MicroGrid", IEEE Power Electronics and Machines in Wind Applications, Denver, July 2012, pp. 18.

[31]. David Gunkel, Tobias Heß, and Peter Schegner," Optimal Scheduling of Decentralized Co-Generation Plants in Micro-Grids", IEEE Power and Energy Society General Meeting, San Diego, July 2012, pp. 1-7.

[32]. S. Kreckelbergh, I. Vechiu," Sizing and dynamic analyses of a micro-grid supplying a harbor industrial area", 16th International Conference on System, Theory, Conrol and Computing, Sinaia, Oct. 2012, pp. 1-5.

[33]. Luigi Martirano, Serena Fornari, Alessandro Di Giorgio and Francesco Liberati, "A case study of a commercial/residential microgrid integrating cogeneration and electrical local users", 12th IEEE International Conference on Environment and Electrical Engineering, Wroclaw, May 2013, pp-363-368.

[34]. A. Kahrobaeian and Yasser A.-R. I. Mohamed," Stability Analysis and Control of Medium-Voltage Micro-Grids with Dynamic Loads", IEEE Power and Energy Society General Meeting,Vancouver, July 2013, pp. 1-5.

[35]. Poria Hasanpor Divshali, Arash Alimardani,Seyed Hossein Hosseinian, and Mehrdad Abed," Decentralized Cooperative Control Strategyof Microsources for Stabilizing Autonomous VSC-Based Microgrids", IEEE transactions on power systems, vol. 27, no. 4,Nov. 2012, pp. 1949- 1959.

[36]. Robert H. Lasseter, Paolo Piagi, "Microgrid: A Conceptual Solution", 35th Annual Power Electronics Specialists Conference, vol. 6,Aachen, Germany, June 2004, pp. 4285- 4290.

[37]. Emmanouil A. Bakirtzis, and Charis Demoulias," Control of a micro grid supplied by renewable energy sources and storage batteries", 20th IEEE International Conference on Electrical Machines, Mar seille, Sep. 2012, pp. 2053- 2059.

[38]. Yujiao LIU, Chuanwen JIANG, Jingshuang SHEN, Xiaobin ZHOU," Energy Management for Grid-connected Micro Grid with Renewable Energies and Dispatched Loads", PRZEGLĄD ELEKTROTECHNICZNY (Electrical Review), ISSN 0033-2097, R. 88 NR 5b/2012

[39]. Huang Xuemei, "Implementing Intelligence and Distributed Execution Mechanism for Flywheel Energy Storage System in Micro Grid", International Conference on 
Electronic \& Mechanical Engineering and Information Technology, Harbin, China, 2011, pp. 413-416.

[40]. Ehsan Nasrolahpour, Meysam Doostizadeh, Hassan Ghasemi," Optimal Management of Micro Grid in Restructured Environment", Second Iranian Conference on Renewable Energy and Distributed Generation, IEEE, Tehran, Mar. 2012, pp. 116- 120.

[41]. Sathish kumar R, Sathish Kumar Kollimalla and Mahesh K. Mishra," Dynamic Energy Management of Micro Grids Using Battery Super Capacitor Combined Storage",Annual IEEE India Conference, Kochi, Dec. 2012, pp. 1078-1083.

[42]. Christoph Molitor, Kanali Togawa, Sebastian Bolte and Antonello Monti," Load Models for Home Energy System and Micro Grid Simulations", 3rd IEEE PES International Conference and Exhibition on Innovative Smart Grid Technologies Europe (ISGT Europe), Berlin, Oct. 2012, pp. 16.

[43]. Quanyuan Jiang, Meidong Xue and Guangchao Geng," Energy Management of Microgrid in Grid-Connected and Stand-Alone Modes", IEEE transactions on power systems, vol. 28, no. 3, August , 2013, pp. 3380- 3389.

[44]. Pukar Mahat, Jorge Escribano Jiménez, Eloy Rodriguez Moldes, Sandra Iren Haug, Ireneusz GrzegorzSzczesny, Karl Eide Pollestad and Luminita Cristiana Totu, "A Micro-Grid Battery Storage Management", IEEE Power and Energy Society General Meeting,Vancouver, July 2013, pp. 1-5.

[45]. M.C Falvo, L. Martirano and D. Sbordone," DSTATCOM with Energy Storage System for Application in Smart Micro-Grids", IEEE International Conference on Clean Electrical Power, Alghero, June 2013, pp. 571- 576.

[46]. ChemNayar, Markson Tang and Wuthipong Suponthana," Wind/PV/Diesel Micro Grid System implemented in Remote Islands in the Republic of Maldives", ICSET, IEEE International Conference on Sustainable Energy Technologies, Singapore, Sep. 2008, pp. 1076- 1080.

[47]. Bai K Blyden, Wei-Jen Lee," Modified Microgrid Concept for Rural Electrification in Africa", IEEE Power Energy Society General Meeting, Montreal, 2006.

[48]. Suraj Baral, Suman Budhathoki and Dr.Hari Prasad Neopane," Grid connection of Micro Hydropower, Mini Grid initiatives and rural electrification policy in Nepal", IEEE International Conference on Sustainable Energy Technologies, Kathmandu, Nepal, Sep. 2012, pp. 66-72.

[49]. G. Buigues, A. Dyśko, V. Valverde, I. Zamora and E. Fernández," Microgrid Protection: Technical challenges and existing techniques", Renewable Energy and Power Quality Journal, No. 11, Bilbao (Spain), Mar. 2013.

[50]. P.Anil Kumar, J.Shankar And Y.Nagaraju," Protection Issues In Micro Grid", International Journal of Applied Control, Electrical and Electronics Engineering (IJACEEE) Vol. 1, May, 2013.

[51]. Won-Seok LEE and Sang-Hee Kang," Protection for Distributed Generations in the DC Micro-grid", IEEE International Conference and Exhibition on Innovative Smart Grid Technologies, Manchester, Dec. 2011,pp. 1-5.
[52]. P.Sailalitha, B.Kiranbabu," SMART GRID”, International Journal of Engineering Trends and Technology (IJETT), Volume4, Issue4, April, 2013.

[53]. MdRazibul Islam, Hossam A. Gabbar," Study of Micro Grid Safety \& Protection Strategies with Control System Infrastructures”, Smart Grid and Renewable Energy ,Scientific Research, 2012.

[54]. Fabio Carastro, Mark Sumner, Pericle Zanchetta," Mitigation of Voltage Dips and Voltage Harmonics within a Micro-grid, using a Single Shunt Active Filter with Energy Storage",32nd Annual Conference on IEEE Industrial Electronics, Paris ,Nov. 2006, pp. 2546-2551.

[55]. Huang Wei, Zhang Jianhua, XieQinghua and $\mathrm{Wu}$ Ziping," The Impact on Power Quality by PWM Converter in Micro-grid", IEEE International Conference on Sustainable Energy Technologies, Singapore, Nov. 2008, pp. 239-245.

[56]. Yun Wei Li and Ching-Nan Kao," An Accurate Power Control Strategy for Power-Electronics-Interfaced Distributed Generation Units Operating in a Low-Voltage Multibus Microgrid", IEEE transactions on power electronics, vol. 24, no. 12, December , 2009, pp. 2977- 2988.

[57]. Mir Nahidul Ambia, Ahmed Al-Durra, Cedric Caruana and S.M.Muyeen," Stability Enhancement of a Hybrid Microgrid System in Grid FaultCondition",15th International Conference on Electrical Machines and Systems, Sapporo, Oct. 2012, pp. 1-6.

[58]. Nikhil K. Ardeshna and Badrul H. Chowdhury," Optimizing Micro-grid Operations in the Presence of Wind Generation",40th IEEE North American Power Symposium, Calgary, Sep. 2008, pp. 1-7.

[59]. P. Bogónez-Franco, J. Balcells, O. Junyent , J. Jordà," SVC Model for Voltage Control of a Microgrid", IEEE International Symposium on Industrial Electronics, Gdansk, June 2011, pp. 1645-1649.

[60]. M. R. Aghaebrahimi, M. Tourani and M. Amiri," Power Consumption Management and Control for Peak Load Reduction in Smart Grids Using UPFC",IEEE Electric Power and Energy Conference, Winnipeg, Oct. 2011, pp. 327-333.

[61]. P.JenoPaul, I Jacob Raglend, T. Ruban Deva Prakash,” Universal Power Line Manager for Micro Grid", International Conference on Recent Advancements in Electrical, Electronics and Control Engineering, Sivakasi, Dec. 2011, pp. 30-35.

[62]. W. Al Habri, Y.L. Abdel Magid, "Power System Stabilizer for Power Sharing Control of Parallel Inverters in a Grid - Connected Micro-grid System", IEEE PES Conference on Smart Grid Technologies, Jiddah, Dec. 2011, pp. 1-8.

[63]. Jing Wang, Zhiqi Wang, LinglingXu and Zongli Wang," A Summary of Applications of D-FACTS onMicrogrid",IEEE Asia Pacific Power And Energy Engineering Conference, Shanghai ,Mar. 2012, pp. 1-6.

[64]. C. Balanuta, I. Vechiuand G. Gurguiatu," Improving Micro-Grid Power Quality Using Three-Phase Four-Wire Active Power Conditioners", International Conference on System, Theory, Control and Computing, Sinaia, Oct. 2012, pp. 1-5. 
[65]. O. Wasynczuk, L. J. Rashkin, B. P. Loop and S. F. Glover," Voltage and Frequency Regulation Strategies in Isolated AC Micro-Grids", IEEE International Conference onCyber Technology in Automation, Control and Intelligent Systems, Thailand, May 2012, pp. 5-10.

[66]. Tuo Dong*, Linchuan Li, ZhengboMa ,"A Combined System of APF and SVC for Power Quality Improvement in Microgrid ", IEEE Power Engineering and Automation Conference, Wuhan, Sep. 2012, pp. 1-4.

[67]. J. Eswaraiah, 1 P. Bhaskara Prasad," Improvement of Dynamic Voltage Stability in a Microgrid by Voltage Stabilizer", International Journal of Modern Engineering Research (IJMER), Vol.2, Issue.6, Nov-Dec. 2012, pp.44244428.

[68]. B.Naresh, V. K.R.MohanRao, Y.Rambabu, " Power Quality Improvement in Microgrid Using Advanced Active Power Conditioner", International Journal of Engineering Research and Development, Volume 8, Issue 8,September 2013, pp. 41-46.

[69]. Jayesh Joglekar,YogeshNerkar," Application of UPFC for Improving Micro-grid Voltage Profile”, IEEE International Conference on Sustainable Energy Technologies , Sri Lanka, Dec 2010, pp. 1-5.

[70]. Waleed Al-Saedi, Stefan W. Lachowicz, Daryoush Habibi and Octavian Bass," Power Quality Improvement in Autonomous Microgrid Operation Using Particle Swarm Optimization", IEEE PES Innovative Smart Grid Technologies, Perth, Nov. 2011, pp. 1-6.

[71]. Alias Khamis, Mohamed, H. Shareef and A. Ayob, “ Modeling And Simulation Of A Microgrid Testbed Using Photovoltaic And Battery Based Power Generation", Journal of Asian Scientific Research , pp. 658-666.

[72]. RoopaRavindran, R. R. Lekshmi," Implementation of grid interface for generation side power management", International Journal of Engineering Research \& Technology (IJERT), Vol. 1 Issue 3, 2012.

[73]. Mojtaba Saeedimoghadam, MajidDehghani, Seyed Mahdi Mousavibadejani and Sayed Mohammad Mousavi G," Simulation and Evaluation of micro-grid synchronization with main network", International Research Journal of Applied and Basic Sciences, 2013.

[74]. H. H. Zeineldin and J.L. Kirtley," Micro-grid Operation of Inverter Based Distributed Generation with Voltage and Frequency Dependent Loads", IEEE Power and Energy Society General Meeting,Calgary, Jul. 2009, pp.1-6.

[75]. BiYing Ren, Xiang Qian Tong, ShaTian, XiangDong Sun," Research on the control strategy of inverters in the micro-grid", IEEE Asia Pacific Power and Energy Engineering Conference, Chengdu, Mar. 2010, pp. 1-4.

[76]. R. Ahshan, M. T. Iqbal, George K. I. Mann and John E. Quaicoe, "Micro-grid System Based on Renewable Power Generation Units", Canadian Conference on Electrical And Computer Engineering, Calgary, 2010, pp. 1-4.

[77]. Sukumar Kamalasadan, Chad M. Tanton," Modeling and Simulation of PEM Fuel Cell Generator as a Micro Grid",
IEEE Industry Application Society Annual Meeting, Houston, Oct. 2010,pp. 1-8.

[78]. A. Arulampalam, N. Mithulananthan, R.C. Bansal, T.K. Saba," Micro-grid Control of PV -Wind-Diesel Hybrid System with Islanded and Grid Connected Operations", IEEE International Conference on Sustainable Energy Technologies ,Sri Lanka, Dec 2010, pp. 1-5.

[79]. YANG Xiu, ZONG Xiang, YANG Fei, ZANG Haiyang," A research on droop control strategy and simulation for the micro-grid", IEEE International Conference on Electrical and Control Engineering, Yichang, Sep. 2011, pp. 5695-5700. [80]. Sun Xiaofeng, LvQingqiu, TianYanjun, ZHE CHEN," An Improved Control Method of Power Electronic Converters in Low Voltage Micro-grid", IEEE International Conference on Electrical Machines and Systems, Beijing, Aug. 2011, pp. $1-6$.

[81]. Lin-Yu Lu, Jian-Hong Liu, Chia-Chi Chu, Yu-Chi Wu and Po-Tai Cheng," Real-Time Simulations of a LaboratoryScale Micro-Grid System in Taiwan", 13th IEEE Workshop on Control and Modelling of Power Electronics, Kyoto, June 2012, pp. $1-8$.

[82]. LIU Jia-jun ,YAO Li-xiao,Tian Dong-meng, LIUBo,LIU Dong, "Study on the Fuzzy Control Strategy Based on Backto-back Micro Grid Connection", IEEE Asia Pacific Power and Energy Engineering Conference, Shanghai, Mar. 2012, pp. 1-5.

[83]. K.M.Abo-Al-EzX.Xia and J.Zhang, "Smart Interconnection Of a Pv/Wind Dg Micro Grid With The Utility Distribution Network", IEEE Proceedings of 9th Industrial and Commercial use of Energy Conference, Stellenbosch, Aug. 2012, pp. 1-8.

[84]. He-Jin Liu, Ke-Jun Li, Hong-Xia Gao, Ying Sun, Kai-qi Sun and Wei-Jen Lee," Control and Simulation of GridConnected Micro-Grid", IEEE Power and Energy Society General Meeting, San Diego, Jul. 2012, pp. 1-6.

[85]. ZhengZeng, Huan Yang, Chong Cheng, ZhiyongZeng, and Rongxiang Zhao," Harmonic and Reactive Currents Sharing by Multi-functional Grid-connected Inverters in a Micro-grid", 15th International Conference on Electrical Machines and Systems, Sapporo, Oct. 2012, pp. 1-5.

[86]. Shailendra Singh, Ajeet Kumar Singh and Saurabh Chanana," Operation and Control of a Hybrid PhotovoltaicDiesel-Fuel Cell System Connected to Micro-Grid", 5th IEEE Power India Conference, Murthal, Dec. 2012, pp. 1-6.

[87]. Xiaoqing Han, Ruifen Cheng, Peng Wang, YanbingJia," Advanced Dynamic Voltage Restorer To Improve Power Quality In Microgrid", IEEE Power and Energy Society General Meeting, Vancouver, Jul. 2013, pp. 1-5.

[88]. Wei-Tzer Huang, Kai-Chao Yao, Chun-Ching Wu, ShyiWen Wang," Dynamic Simulation and Analysis of a LowVoltage Micro-Grid", International Conference on Computing, Measurement, Control and Sensor Network, Taiyuan, Jul. 2012, pp.245-248. 


\section{BIOGRAPHIES}

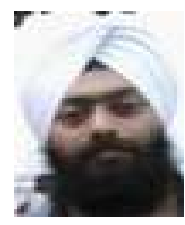

Abinash Singh is a research scholar in the Electrical Engineering Department, PEC University of Technology, Chandigarh "formerly Punjab Engineering College, Chandigarh". The author received B.Tech. (Electrical) in2008 from Punjab Technical University, Jalandhar , M.E (Electrical Engineering) from PEC University of Technology, Chandigarh and is now pursuing $\mathrm{Ph}$ D. under the guidance of Dr.Balwinder Singh Surjan ,on regular basis in the same institute. He has two years of professional teaching experience to undergraduate students in Punjab Technical University. His areas of interest are power system and power quality improvement.

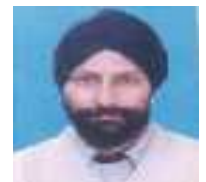

Surjan Balwinder Singh is Associate Professor in the Electrical Engineering Department, PEC University of Technology, Chandigarh "formerly Punjab Engineering College, Chandigarh". The author received B.E. (Electrical) in 1989, M. Tech. (Power Apparatus \& Systems) in Feb 1991, and Ph.D. degrees in 2008, from Shivaji University Kolhapur, I.I.T. Bombay, and Panjab University Chandigarh respectively. He has twenty years of professional teaching experience in the same institute. He has taught undergraduate and post graduate students. He has guided number of post graduate theses mainly in the field of power system stability studies also in field of photometric analysis of luminaires. His areas of interest include power system stability studies, illumination engineering, machine applications, modeling and analysis. The author is member of professional societies like IEEE, Indian Society of Lighting Engineering (M), Fellow Institution of Engineers (I), Chartered Engineer IE (I). 